\title{
Five-Level Reduced-Switch-Count Boost PFC Rectifier with Multicarrier PWM
}

\author{
Hani Vahedi, Student, IEEE, Ali Asghar Shojaei, Ambrish Chandra, Fellow, IEEE, Kamal Al-Haddad, Fellow, IEEE
}

\begin{abstract}
A multilevel boost PFC (Power Factor Correction) rectifier is presented in this paper controlled by cascaded controller and multicarrier pulse width modulation technique. The presented topology has less active semiconductor switches compared to similar ones reducing the number of required gate drives that would shrink the manufactured box significantly. A simple controller has been implemented on the studied converter to generate a constant voltage at the output while generating a five-level voltage waveform at the input without connecting the load to the neutral point of the DC bus capacitors. Multicarrier PWM technique has been used to produce switching pulses from control signal at a fixed switching frequency. Multi-level voltage waveform harmonics has been analyzed comprehensively which affects the harmonic contents of input current and the size of required filters directly. Full experimental results confirm the good dynamic performance of the proposed five-level PFC boost rectifier in delivering power from $\mathrm{AC}$ grid to the DC loads while correcting the power factor at the AC side as well as reducing the current harmonics remarkably.
\end{abstract}

Index Terms-Multilevel Converter, Active Rectifier, Multicarrier PWM, Cascaded Control, Power Quality.

\section{INTRODUCTION}

High power factor or PFC boost converters are one of the mostly used equipment in the industries. The main concerns of such converters are the unity power factor operation and low harmonic distortion of the input $\mathrm{AC}$ waveforms that can be ensured by generating a DC voltage higher than the grid peak voltage amplitude, which makes use of switching devices inevitable [1-3]. Conventional two-level rectifiers known as full bridge converters have been working for many decades satisfactorily, however they are being replaced by emerging multilevel converter technologies [4].

Manuscript received November 4, 2015; revised April 14, 2016 accepted May 27, 2016. This work has been supported by the Canadian Research Chair in Electric Energy Conversion and Power Electronics (CRC-EECPE) and the Natural Sciences and Engineering Research Council of Canada (NSERC).

H. Vahedi, A. Chandra and K. Al-Haddad are with the Ecole de Technologie Superieure, University of Quebec, Montreal, Quebec, Canada H3C 1K3 (email: hani.vahedi@etsmtl.ca, ambrish.chandra@etsmtl.ca, kamal.al-haddad@etsmtl.ca)

A.A. Shojaei is an assistant professor at Department of Electrical Engineering, Islamic Azad University, Neyshabur branch, Neyshabur, Iran (shojaei2012@gmail.com)
Multilevel converters produce more voltage levels decreasing the voltage and current harmonics significantly while operating at lower switching frequency. They are comprehensively investigated as DC-AC energy conversion mode and now they have found many applications in AC-DC power conversion systems called rectifier [5-10].

Most of the works have been performed on two-stage rectifiers in which the input $\mathrm{AC}$ voltage were rectified by a diode bridge and then a DC-DC chopper were used to change the DC voltage level at the second stage output. The main drawback of such system is the high switching frequency of active devices leads to high switching losses, audio noise and requiring bulky filters $[11,12]$. On the other hand, active bridge rectifier could provide high power factor but the switching loss, filter size and current/voltage harmonic contents are still matters of concerns [13-16]. Considering proved advantages of multilevel converters such as low switching frequency, low harmonic distortion and high power conversion, they have been widely used in various industries [17-19]. Many multilevel rectifiers called bridgeless topologies are studied in the literature mainly including threelevel ones [20-24]. Some five-level topologies have been also introduced that are using hysteresis current control or another complicated controllers that makes switching frequency higher than standard levels results in higher power losses and lower efficiency. Moreover, for medium voltage applications, high switching frequency is an important limit over choosing proper devices [25-30].

In this paper, a five-level boost PFC rectifier has been proposed using reduced number of active switches that affects the size of the manufactured box significantly [31]. On the other hand, gaining from multilevel converter advantages makes the presented rectifier appealing to use in mediumvoltage high-power applications in which the switches suffer low voltage stresses and are operated at low switching frequency. Moreover, low harmonic content of the AC voltage and current would be a promising result of employing this 5level PFC rectifier. To overcome the high switching frequency, a 4-carrier PWM technique has been adopted to modulate the reference signal and send associated switching pulses since this technique is still the most interesting method in industries. It should be noted that the reference signal is calculated by a simple cascaded controller in which two voltage and current loops are designed to regulate the output DC voltage, to make the input voltage and current in-phase and to generate 5-level voltage waveform at the rectifier input. 
It should be noted that DC capacitors middle point is not connected to the load which is impossible in industrial practical applications. Full test results including change in the load, AC voltage fluctuation and generating different DC voltage values validate effective functionality of the proposed 5-level boost PFC rectifier, designed multicarrier PWM technique and simple controller in producing low ripple DC voltage at the output while drawing unity power factor and low harmonic current from the input along with operating at low and fixed switching frequency.

\section{Proposed Five-LeVel Reduced-Switch ReCtifIER}

Fig. 1 shows the proposed five-level boost PFC rectifier in which three active switches and six diodes have been used as a slight modification to a similar topology that includes four switches [32].

As is clear in Fig. 1, a bidirectional switch has been connected between leg $\mathrm{b}$ and midpoint of DC capacitors to provide different paths for current in order to produce five voltage levels at the output including $\pm \mathrm{V}_{\mathrm{dc}}, \pm \mathrm{V}_{\mathrm{dc}} / 2$ and 0 where $V_{\mathrm{dc}}$ is the output DC voltage generated by the rectifier. The bidirectional switch is made by four diodes and one active switch to replace active parts with diodes. The full switching states are listed in table I along with the associate generated voltage level.

Noticing table I, it can be said that based on current direction, different voltage levels would be produced by firing necessary switches. If the current is positive, turning ON the switch $S_{1}$ leads to conducting the diode $D_{2}$ so $+V_{\text {dc }}$ will be appeared at $\mathrm{V}_{\mathrm{ab}}$ and both capacitors $\left(\mathrm{C}_{1} \& \mathrm{C}_{2}\right)$ are charged up. In next switching state, by firing switches $S_{1}$ and $S_{3}$ simultaneously, a low impedance current path would be provided through $\mathrm{C}_{1}$ and bidirectional switch $\mathrm{S}_{3}$ so the upper capacitor would be charged and $\mathrm{V}_{\mathrm{ab}}$ will have the voltage level of $+\mathrm{V}_{\mathrm{dc}} / 2$. The zero level would be generated by a short circuit between points a and $b$ using switches $S_{1}$ and $S_{2}$. For negative current direction, $D_{1}$ is mostly responsible to prepare required current path. Hence, by turning ON the $\mathrm{S}_{3}$, the current will pass through only the lower capacitor $\mathrm{C}_{2}$ and charges it up while $\mathrm{D}_{1}$ is conducting and the negative voltage level $-\mathrm{V}_{\mathrm{dc}} / 2$ would be generated at the rectifier input. Finally, during negative current direction, if switch $S_{2}$ is fired, then diode $D_{1}$ conducts and $\mathrm{V}_{\mathrm{ab}}$ would be equal to $-\mathrm{V}_{\mathrm{dc}}$. Having no redundancy switching states is the most important problem of this topology which makes the dc capacitors voltages balancing very difficult.

To prove the advantage of multilevel converters in generating lower harmonic components, some typical multilevel waveforms have been generated and analyzed by FFT. Fig. 2 demonstrates different waveforms with increasing levels and it is evident that the THD will decrease around 50\% by adding one level due to making the waveform more similar to sine wave.

In a grid-connected application, the converter voltage imposes its harmonics into the current waveform. Therefore, regarding table I, the proposed rectifier would have 5-level voltage waveform at the input so it will generate low harmonics affecting the grid current directly results in using smaller size filters compared to the conventional two-level or two-stage rectifiers. Reduced size of passive components results in light weight and cheaper manufacturing cost of the converter remarkably.

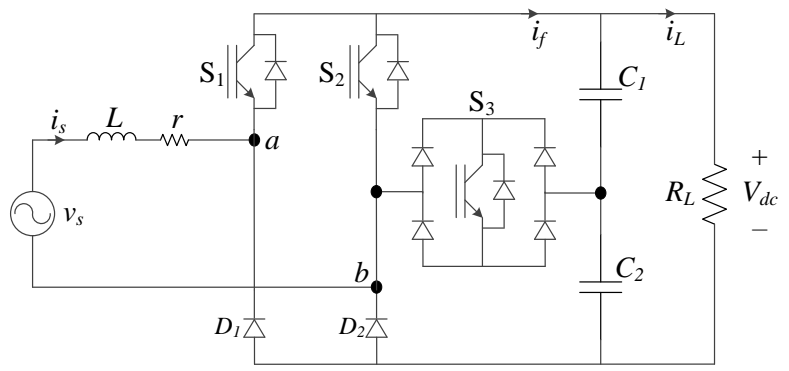

Fig. 1. Proposed five-level boost PFC rectifier with reduced number of switches

TABLE I

SWITCHING STATES AND PRODUCED VOLTAGE LEVELS OF PROPOSED FIVE-LEVEL RECTIFIER

\begin{tabular}{cccccc}
\hline $\begin{array}{c}\text { Switching } \\
\text { States }\end{array}$ & $\boldsymbol{i}_{\boldsymbol{s}}$ & $\mathbf{S}_{\mathbf{1}}$ & $\mathbf{S}_{\mathbf{2}}$ & $\mathbf{S}_{\mathbf{3}}$ & $\mathbf{V}_{\mathrm{ab}}$ \\
1 & $>0$ & 1 & 0 & 0 & $+\mathrm{V}_{\mathrm{dc}}$ \\
2 & $>0$ & 1 & 0 & 1 & $+\mathrm{V}_{\mathrm{dc}} / 2$ \\
3 & $\geq 0 \& \leq 0$ & 1 & 1 & 0 & 0 \\
4 & $<0$ & 0 & 0 & 1 & $-\mathrm{V}_{\mathrm{dc}} / 2$ \\
5 & $<0$ & 0 & 1 & 0 & $-\mathrm{V}_{\mathrm{dc}}$ \\
\hline \hline
\end{tabular}
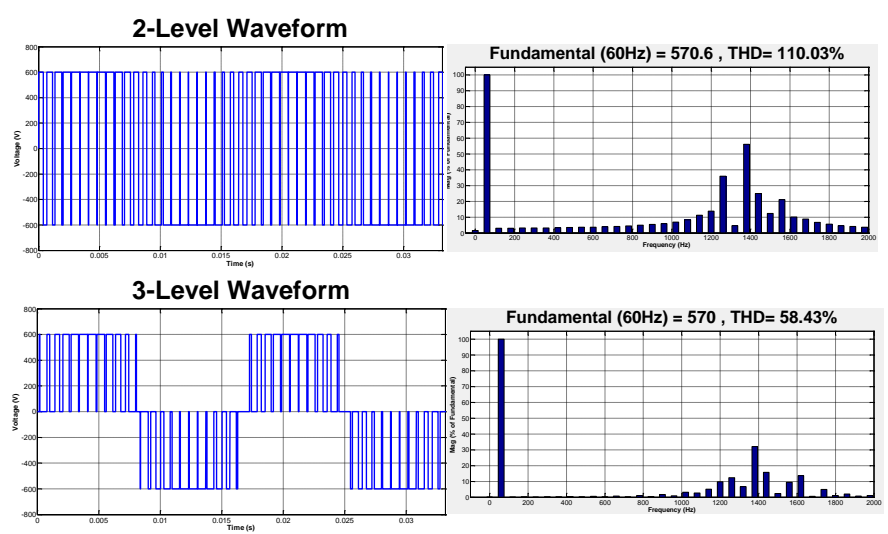

5-Level Waveform

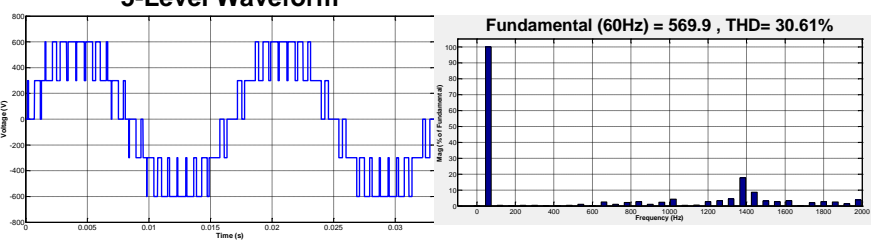

Fig. 2. Multilevel waveforms and corresponding harmonic spectrum

\section{CONTROLlER AND MOdUlation TECHNIQUE}

\section{A. Cascaded Control Design}

Using hysteresis current control can help shaping the grid current into a sine wave but imposes switching problems such as high and variable switching frequency which makes 
annoying noises and increasing power losses in the hardware implementation [32, 33]. In order to make this rectifier topology appealing and useable by industries, a simple controller including two cascaded loops have been designed in which the outer loop is voltage regulator and the inner one is the current controller. Initially, the AC line average current is modeled as shown by equation (1) [29, 31, 34, 35].

$$
\begin{aligned}
L \frac{d i_{s}}{d t} & =v_{s}-r \times i_{s}-V_{a b} \\
& =v_{s}-r \times i_{s}-\alpha V_{d c}
\end{aligned}
$$

Where, all variables can be seen in Fig. 1 . L is the line inductor and $\mathrm{r}$ is that inductor parasitic resistance. $\alpha$ is the duty cycle of the rectifier. By assuming a constant value for grid voltage $\left(v_{s}\right)$, and averaged value of current and duty cycle, small signal model of Eq. (1) can be converted into Laplace form as:

$$
L s i_{s}=-r i_{s}-\alpha V_{d c}
$$

Since the inner loop should be at least 5 times faster than the outer loop, therefor the outer loop value which is the DC voltage could be considered constant. Using a reference value for DC voltage as $V_{d c}{ }^{*}$, the following transfer function is obtained for the grid-connected rectifier inner loop giving the information that the output $\mathrm{DC}$ voltage, inductive filter value and line impedance affects the system AC current.

$$
H_{\text {rec.in }}(s)=\frac{i_{s}}{\alpha}=\frac{-V_{d c}^{*}}{L s+r}
$$

Thus, the current control can be a simple gain as a proportional controller. Fig. 3 shows the inner loop of the controller.

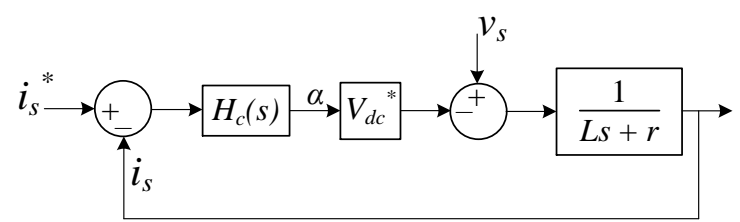

Fig. 3. Inner loop of the designed controller

The current controller $H_{c}(s)$ can be either a simple gain as proportional controller or a PI controller but it should be mentioned that the inner loop should have faster dynamic than the outer loop. Therefore, in case of using a PI controller for sinusoidal input current signal, the integral gain $\left(k_{i c}\right)$ of that PI should be small enough not affecting the speed of that inner loop. However, using a PI compensator on a sinusoidal signal causes some steady-state errors which can be observed in the current harmonic spectrum as a DC component however it can do the job eventually. One alternative for such case is a proportional resonant (PR) controller that has an infinite gain at fundamental frequency (e.g. $60 \mathrm{~Hz}$ in this work) and shows zero steady-state error [36].
In continue, to control the output DC voltage, another loop should be added to the controller which was mentioned as outer loop earlier. To obtain the system model for outer loop, equations from DC side of the rectifier should be investigated.

$$
\begin{aligned}
i_{f} & =i_{C}+i_{L} \\
& \rightarrow C \frac{d V_{d c}}{d t}=k \cdot i_{s}-\frac{V_{d c}}{R_{L}}
\end{aligned}
$$

$k$ is a constant average value for duty cycle and it is close to 1. $i_{c}$ is the DC capacitor current (consider one capacitor $\mathrm{C}$ equals to $2 \mathrm{C}_{1}$ connected in parallel to $\mathrm{C}_{1} \& \mathrm{C}_{2}$ ). By small signal modelling of Eq. (4) and converting into s-plane, the following transfer function for the outer loop system would be achieved. This transfer function shows the relation between output DC voltage and the value of the load and DC capacitor.

$H_{\text {rec.out }}(s)=\frac{V_{d c}}{i_{s}}=\frac{k R_{L}}{R_{L} C s+1}$

Due to the relation between $i_{s}$ and $V_{d c}$ as Eq. (5), the voltage controller can be considered as outer loop. Such loops give the idea of cascaded controller in which the output of outer loop is an input for the inner loop.

Since the DC signal does not contain any frequency, a PI compensator with transfer function of $H_{v}(s)$ is used to regulate the voltage at the desired level. As shown in Fig. 4, the voltage controller loop is in charge of regulating the output DC voltage at $V_{d c}{ }^{*}$ and provides the peak value of the reference current as an input to the inner loop.

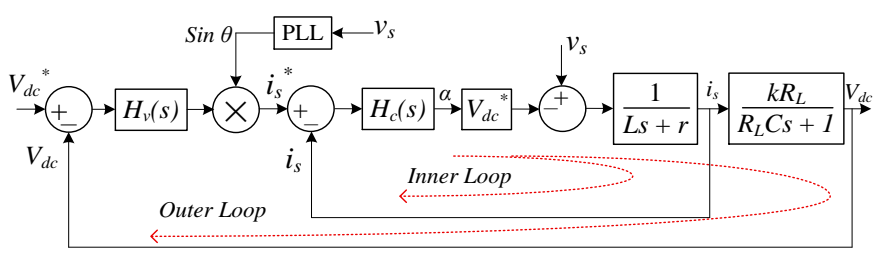

Fig. 4. Designed cascaded control block diagram applied on 5-level rectifier

Regarding Fig. 4, more details are given to derive the whole system open-loop transfer function $\left(H_{o p}(s)\right)$. It should be mentioned that at first the inner loop transfer function has to be calculated by multiplying the plant model and the compensator $H_{c}(s)$. PI controller has been chosen for the inner loop to show the detailed calculations but $k_{i c}$ is selected small enough to have higher speed at inner loop in further analysis.

$$
\begin{aligned}
H_{c}(s)= & k_{p c}+\frac{k_{i c}}{s}=\frac{k_{p c} s+k_{i c}}{s} \\
H_{\text {in.ol }}(s) & =H_{c}(s) \times \frac{V_{d c}^{*}}{L s+r} \\
& =\frac{k_{p c} V_{d c}^{*} s+k_{i c} V_{d c}^{*}}{L s^{2}+r s}
\end{aligned}
$$


$H_{\text {in.ol }}(s)$ demonstrates the open-loop transfer function of the inner loop controlled by the current controller of $H_{c}(s)$. To derive the whole system model, the closed-loop transfer function of $H_{\text {in.ol }}(s)$ should be calculated as:

$$
\begin{aligned}
H_{\text {in.cl }}(s) & =\frac{H_{\text {in.ol }}(s)}{1+H_{\text {in.ol }}(s)} \\
& =\frac{k_{p c} V_{d c}^{*} s+k_{i c} V_{d c}^{*}}{L s^{2}+k_{p c} V_{d c}^{*} s+r s+k_{i c} V_{d c}^{*}} \\
& =\frac{k_{p c} s+k_{i c}}{\left(\frac{L}{V_{d c}^{*}}\right)^{2}+\left(k_{p c}+\frac{r}{V_{d c}^{*}}\right) s+k_{i c}} \\
H_{v}(s)= & k_{p v}+\frac{k_{i v}}{s}=\frac{k_{p v} s+k_{i v}}{s}
\end{aligned}
$$

Equation (8) gives a transfer function of the inner system which should be compensated by a voltage controller of Eq. (9) and multiplied by the outer loop model. Thus:

$$
H_{o p}(s)=H_{v}(s) \times H_{\text {in.cl }}(s) \times H_{\text {rec.out }}(s)
$$

Open-loop transfer function of the whole system with cascaded PI controller has been derived as Eq. (10). Using some specific gains results in simplifying the transfer function in which it can operate as a first order system with a reliable performance. Thus, the controller designer should consider all conditions and compute the gains accordingly. The controller shown in Fig. 4 can be implemented on real-time controllers due to low complexity and sufficient accuracy.
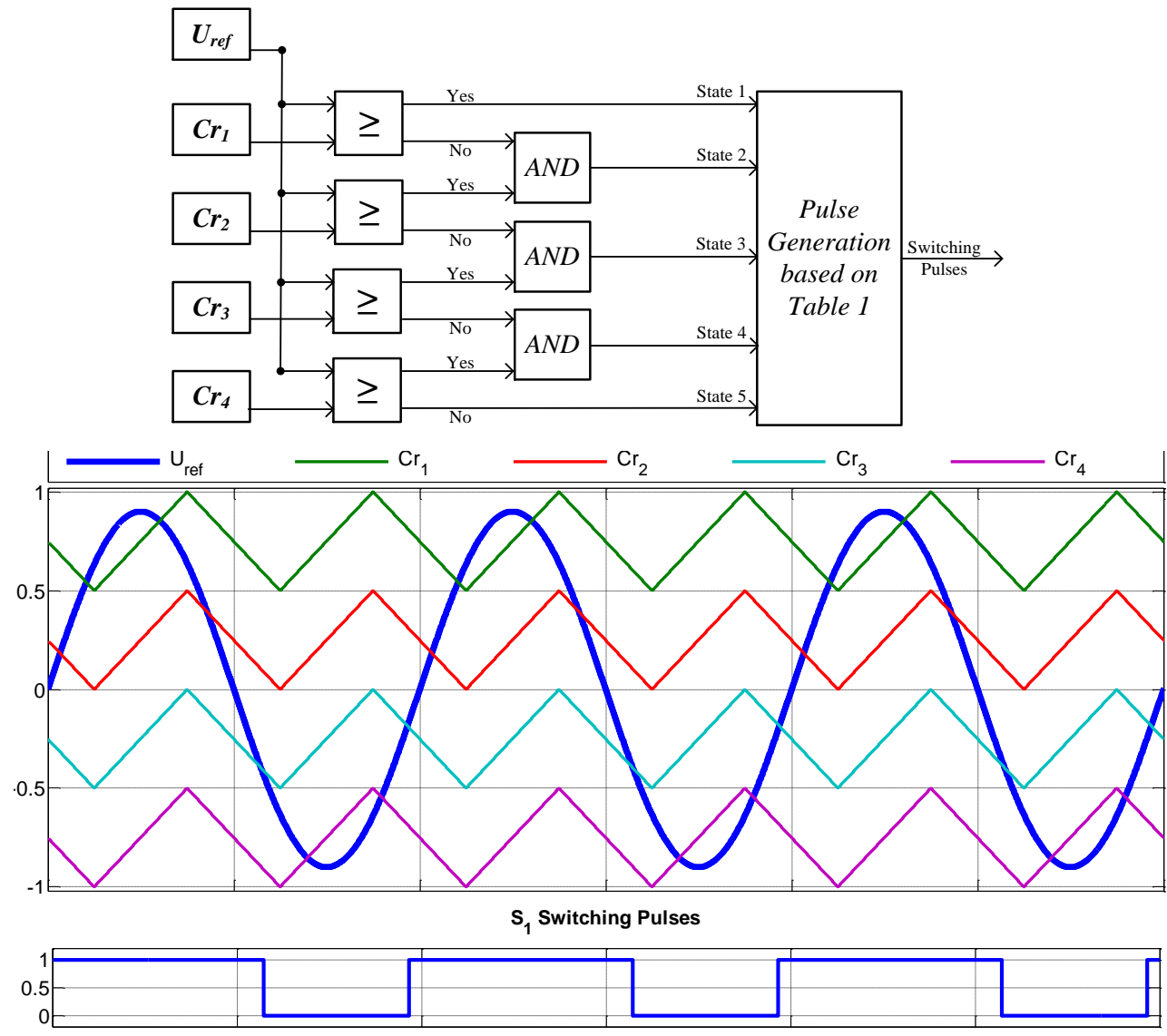

$\mathrm{S}_{2}$ Switching Pulses

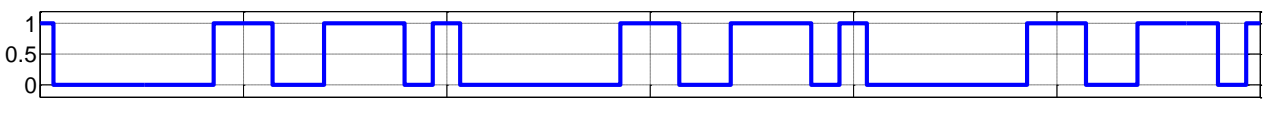

$\mathrm{S}_{3}$ Switching Pulses

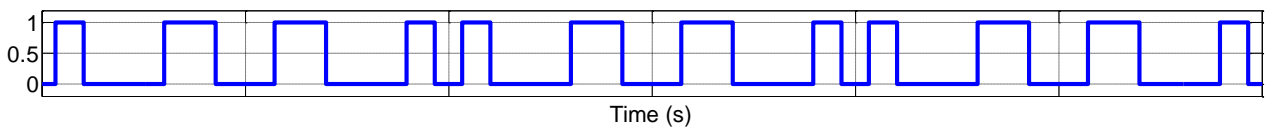

Fig. 5. proposed multicarrier PWM technique for low and fixed switching frequency purposes 


\section{B. Multicarrier PWM Technique}

In order to have low and fixed switching frequency to be suitable for high power and industrial applications, the PWM method should be used to generate required switching pulses $[37,38]$. It should be noted that other switching techniques like hysteresis has variable switching frequency which makes annoying audible noises. As illustrated in Fig. 5, four carriers $\left(\mathrm{Cr}_{1}, \mathrm{Cr}_{2}, \mathrm{Cr}_{3}\right.$ and $\left.\mathrm{Cr}_{4}\right)$ are shifted vertically to modulate the calculated reference signal $\left(\mathrm{U}_{\text {ref }}\right)$. Each carrier is responsible of producing pulses for associate voltage level and switching states as shown by logic blocks. Moreover, corresponding switching pulses for three cycles of the modulated waveform $\left(U_{\text {ref }}\right)$ have been depicted in Fig. 5 to demonstrate the fixed switching frequency in each cycle The proposed method ensures low and fixed switching frequency functionality of the 5-level converter aims at low switching losses and high efficiency compared to other topologies.

\section{EXPERIMENTAL RESULTS}

To show the good dynamic performance of the proposed rectifier as well as the implemented controller and modulation technique, it has been tested in the Lab under various conditions. The controller and switching technique have been implemented on dSpace 1103 and a sampling of $20 \mu$ s has been achieved due to the simple controller algorithm.

At first the steady-state operation of the rectifier with implemented controller and switching technique has been shown in Fig. 6. The rectifier is fed from a 120V RMS grid while $i_{s}$ is synchronized with $v_{s}$ ensuring unity power factor mode of operation. 5-level voltage waveform at the input of the rectifier is illustrated in that figure containing low harmonic pollution which affects the grid current THD positively. $40 \Omega$ load is connected at the DC side and $\mathrm{V}_{\mathrm{dc}}$ is fixed at $200 \mathrm{~V}$ with acceptable voltage ripple around $6.9 \mathrm{~V} . \mathrm{V}_{\mathrm{C} 1}$ and $\mathrm{V}_{\mathrm{C} 2}$ have been balanced identically that made a symmetrical 5-level voltage waveform of $\mathrm{V}_{\mathrm{ab}}$ with levels of $0 \mathrm{~V}, \pm 100 \mathrm{~V}$ and $\pm 200 \mathrm{~V}$. Grid side information including AC voltage/current waveforms, their RMS and THD\% values, input active/reactive power and the power factor have been captured using AMEC power analyzer and displayed in Fig. 7. The AC current THD is almost $1.3 \%$ which is acceptably less than standard level (5\%) [39]. It is also evident from Fig. 7 that the rectifier has been tested almost at $1 \mathrm{~kW}$ power rating with the unity power factor.

In order to simulate the transient modes, different tests have been performed to verify the good dynamic performance of proposed converter with implemented controller. As shown in Fig. 8 a $50 \%$ change in the load has been made suddenly which is the most happening case in rectifier systems. Although $i_{s}$ is increased due to reducing the load from $78 \Omega$ to $38 \Omega$, the load voltage has been stabilized quickly at $200 \mathrm{~V}$ as well as the rectifier is still working in unity power factor mode.
TABLE II SYSTEM PARAMETERS

\begin{tabular}{lc}
\hline \hline AC Grid Voltage & $120 \mathrm{~V} \mathrm{RMS}$ \\
AC Grid Frequency & $60 \mathrm{~Hz}$ \\
Interface Inductor & $2.5 \mathrm{mH}$ \\
DC voltages $\left(\mathrm{V}_{\mathrm{dc}}\right)$ & $200 \mathrm{~V}$ \\
DC Capacitor $\left(\mathrm{C}_{1} \& \mathrm{C}_{2}\right)$ & $1000 \mathrm{uF}$ \\
DC Load $\left(\mathrm{R}_{\mathrm{L}}\right)$ & $78 \Omega$ and $38 \Omega$ \\
Switching Frequency & $5 \mathrm{kHz}$ \\
\hline \hline
\end{tabular}

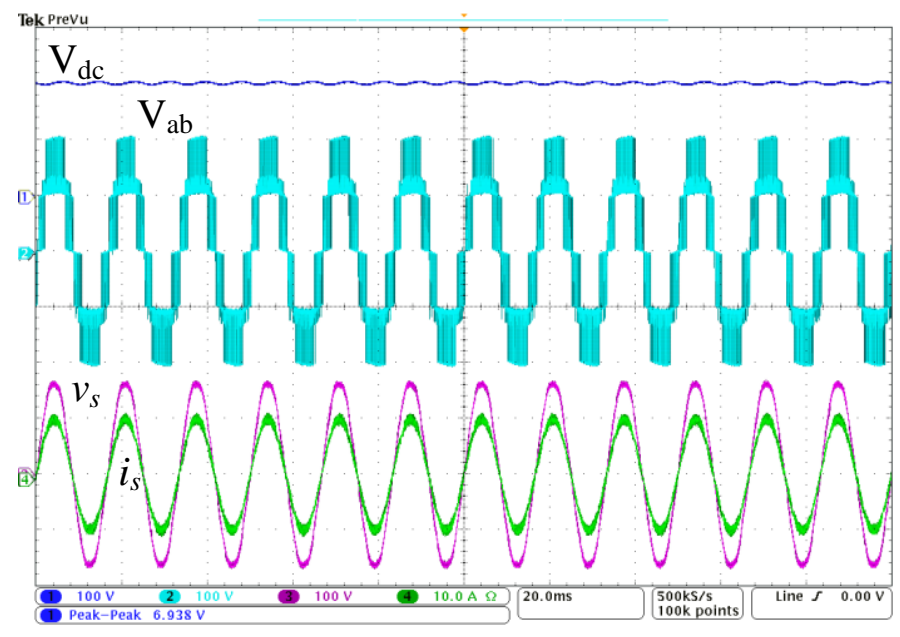

Fig. 6. Experimental results from steady-state operation of the rectifier

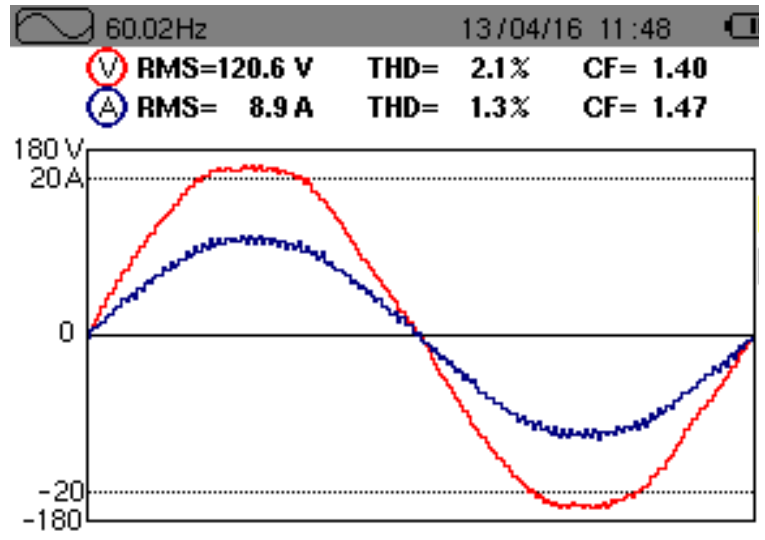

a)
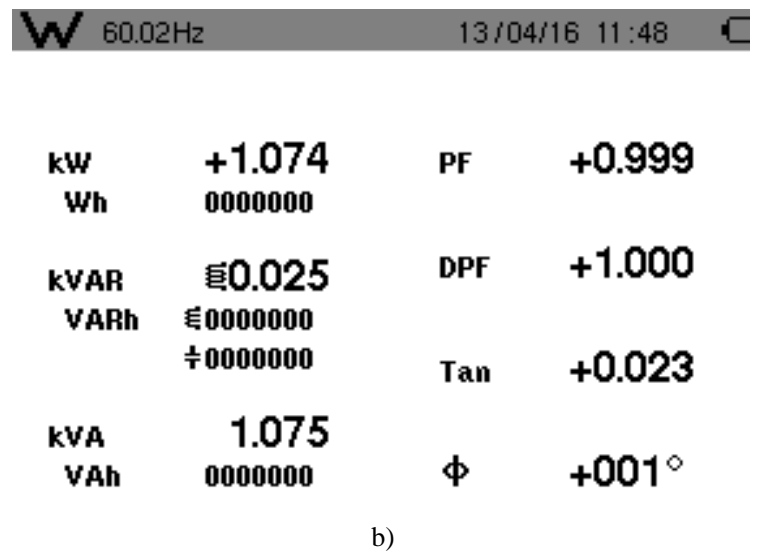

Fig. 7. a) RMS value and THD\% of the grid voltage $\left(v_{s}\right)$ and current $\left(i_{s}\right)$ b) power measurements at the $\mathrm{AC}$ grid side 


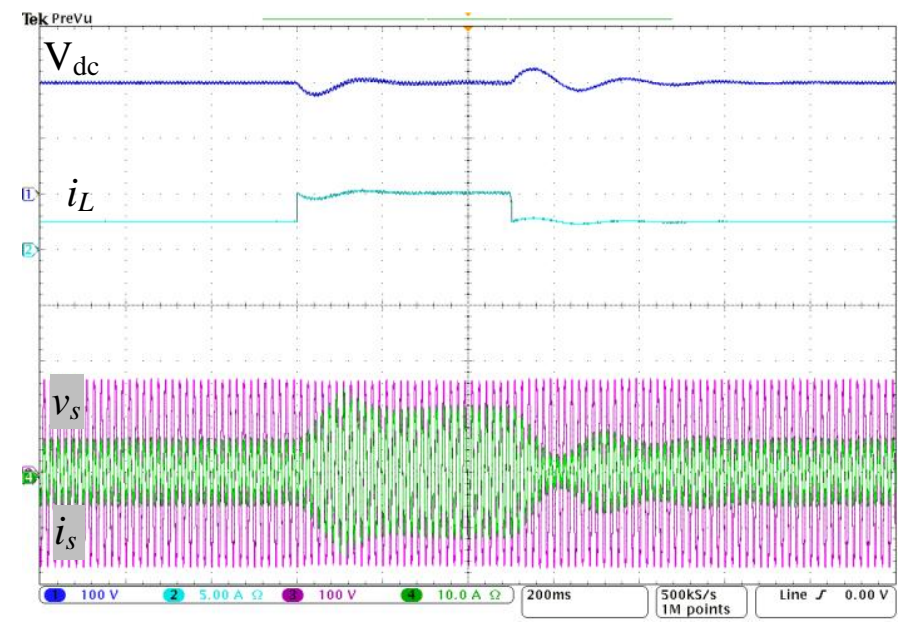

Fig. 8. Experimental results during $50 \%$ increase in the load

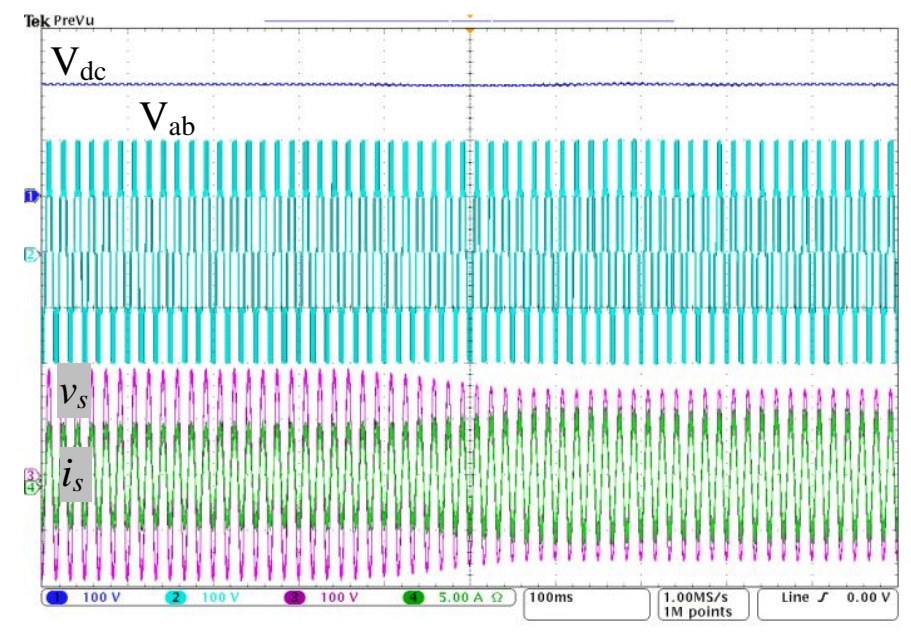

Fig. 9. Experimental results during AC source voltage variation

In another case, the input $\mathrm{AC}$ voltage has been changed as an unwanted problem in the utility. As illustrated in Fig. 9, the DC side power consumption $\left(\mathrm{V}_{\mathrm{dc}} \times i_{L}\right)$ is not varied but $v_{s}$ has been decreased, therefore $i_{s}$ is increased proportional to the power delivered to the load smoothly. DC capacitors voltages have not been affected during such common voltage sag in the grid.

Eventually for the last test, the DC voltage reference $\left(\mathrm{V}_{\mathrm{dc}}{ }^{*}\right)$ has been increased by $25 \%$ from $200 \mathrm{~V}$ to $250 \mathrm{~V}$ to check the tracking performance of the controller. Results have been depicted in Fig. 10 in which all values except $v_{s}$ have been increased accordingly. The controller tracked the new reference voltage value in less than $0.3 \mathrm{~s}$ quickly.

Various conditions have been applied on the running system to investigate the dynamic performance of the proposed rectifier with implemented cascaded controller and switching technique. Low harmonic 5-level waveform of the rectifier as well as fixed switching frequency as an achievement of using multicarrier technique make this work interesting for power industries.

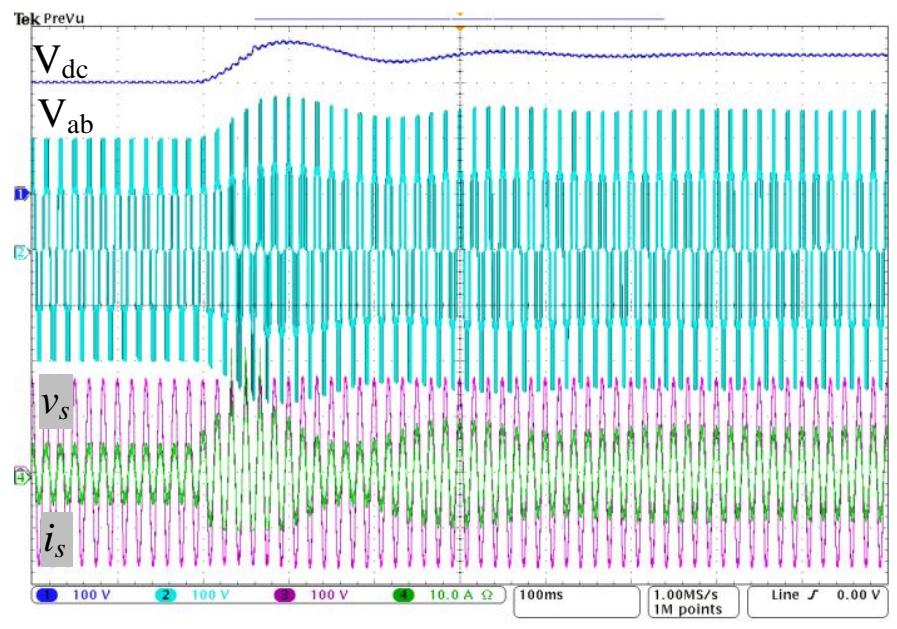

Fig. 10. Experimental results during $25 \%$ raise in the DC voltage reference

\section{CONCLUSION}

In this paper a reduced switch count 5-level boost PFC rectifier has been presented. A cascaded PI controller has been designed to regulate the output DC voltage and to ensure the unity power factor mode of the input $\mathrm{AC}$ voltage and current. Moreover, low harmonic AC current waveform has been achieved by the implemented controller and employing a small inductive filter at the input line. One of the main issues of switching rectifiers is the high switching frequency that has been reduced in this work using PWM technique through adopting multicarrier modulation scheme. Moreover, DC capacitors middle point has not been connected to the load that had required splitting the load to provide a neutral point. Using a single load with no neutral point makes this topology practical in real applications. Comprehensive experimental tests including change in the load, AC voltage fluctuation and generating different DC voltage values have been performed to ensure the good dynamic performance of the rectifier, adopted controller and switching technique. Moreover, the low THD of the input current has been measured to validate the advantage of multilevel waveforms in reducing harmonic contents and consequently diminishing the size of required filters at the input of the converters.

\section{REFERENCES}

[1] B. Singh, B. N. Singh, A. Chandra, K. Al-Haddad, A. Pandey, and D. P. Kothari, "A review of three-phase improved power quality AC-DC converters," Industrial Electronics, IEEE Transactions on, vol. 51, no. 3, pp. 641-660, 2004.

[2] M. Mobarez, M. Kashani, and S. Bhattacharya, "A Novel Control Approach For Protection of Multi-Terminal VSC Based HVDC Transmission System Against DC Faults," IEEE Trans. Ind. Applications, vol. PP, no. 99, pp. 1-1, 2016.

[3] H. Mortazavi, H. Mehrjerdi, M. Saad, S. Lefebvre, D. Asber, and L. Lenoir, "A Monitoring Technique for Reversed Power Flow Detection With High PV Penetration Level," IEEE Trans. Smart Grid, vol. 6, no. 5, pp. 2221-2232, 2015.

[4] H. Abu-Rub, M. Malinowski, and K. Al-Haddad, Power electronics for renewable energy systems, transportation and industrial applications: John Wiley \& Sons, 2014. 
[5] H. Vahedi, H. Y. Kanaan, and K. Al-Haddad, "PUC converter review: Topology, control and applications," in IECON 2015-41st Annual Conference of the IEEE Industrial Electronics Society, Japan, 2015, pp. 4334-4339.

[6] S. Kouro, M. Malinowski, K. Gopakumar, J. Pou, L. G. Franquelo, B. Wu, J. Rodriguez, M. A. Perez, and J. I. Leon, "Recent advances and industrial applications of multilevel converters," IEEE Trans. Ind. Electron., vol. 57, no. 8, pp. 2553-2580, 2010.

[7] H. Vahedi, P. Labbe, and K. Al-Haddad, "Sensor-Less Five-Level Packed U-Cell (PUC5) Inverter Operating in Stand-Alone and GridConnected Modes," IEEE Trans. Ind. Informat., vol. 12, no. 1, pp. 361-370, 2016.

[8] M. Sharifzadeh, H. Vahedi, R. Portillo, M. Khenar, A. Sheikholeslami, L. G. Franquelo, and K. Al-Haddad, "Hybrid SHMSHE Pulse Amplitude Modulation for High Power Four-Leg Inverter," IEEE Trans. Ind. Electron., vol. PP, no. 99, pp. 1-1, 2016.

[9] J. Leon, S. Kouro, L. G. Franquelo, J. Rodriguez, and B. Wu, "The Essential Role and the Continuous Evolution of Modulation Techniques for Voltage Source Inverters in Past, Present and Future Power Electronics," IEEE Trans. Ind. Electron., vol. PP, no. 99, pp. 1-1, 2016.

[10] H. Vahedi and K. Al-Haddad, "METHOD AND SYSTEM FOR OPERATING A MULTILEVEL INVERTER," US Patent 20160126862, 2015.

[11] M. M. Jovanovic and Y. Jang, "State-of-the-art, single-phase, active power-factor-correction techniques for high-power applications-an overview," Industrial Electronics, IEEE Transactions on, vol. 52, no. 3, pp. 701-708, 2005.

[12] P. Kong, Y. Jiang, and F. C. Lee, "Common mode EMI noise characteristics of low-power AC-DC converters," Power Electronics, IEEE Transactions on, vol. 27, no. 2, pp. 731-738, 2012.

[13] H. Kanaan, K. Al-Haddad, A. Hayek, and I. Mougharbel, "Design, study, modelling and control of a new single-phase high power factor rectifier based on the single-ended primary inductance converter and the Sheppard-Taylor topology," IET Power Electronics, vol. 2, no. 2, pp. 163-177, 2009.

[14] H. Wu and X. He, "Single phase three-level power factor correction circuit with passive lossless snubber," Power Electronics, IEEE Transactions on, vol. 17, no. 6, pp. 946-953, 2002.

[15] O. Garcia, J. A. Cobos, R. Prieto, P. Alou, and J. Uceda, "Single phase power factor correction: a survey," Power Electronics, IEEE Transactions on, vol. 18, no. 3, pp. 749-755, 2003.

[16] H. Y. Kanaan and K. Al-Haddad, "Three-Phase Current-Injection Rectifiers: Competitive Topologies for Power Factor Correction," IEEE Ind. Electron. Mag., vol. 6, no. 3, pp. 24-40, 2012.

[17] P. Qashqai, A. Sheikholeslami, H. Vahedi, and K. Al-Haddad, "A Review on Multilevel Converter Topologies for Electric Transportation Applications " in VPPC 2015-Vehicular Power and Propulsion Conference, Canada, 2015, pp. 1-6.

[18] G. Falahi, W. Yu, and A. Q. Huang, "THD minimization of modular multilevel converter with unequal DC values," in IEEE Energy Conversion Congress and Exposition (ECCE), 2014, pp. 2153-2158.

[19] G. Falahi and A. Huang, "Low voltage ride through control of modular multilevel converter based HVDC systems," in 40th Annual Conference of the IEEE Industrial Electronics Society (IECON), 2014, pp. 4663-4668.

[20] L. Yacoubi, K. Al-Haddad, L.-A. Dessaint, and F. Fnaiech, "Linear and nonlinear control techniques for a three-phase three-level NPC boost rectifier," Industrial Electronics, IEEE Transactions on, vol. 53, no. 6, pp. 1908-1918, 2006.

[21] C. Xia, X. Gu, T. Shi, and Y. Yan, "Neutral-point potential balancing of three-level inverters in direct-driven wind energy conversion system," IEEE Trans. Energy Conversion, vol. 26, no. 1, pp. 18-29, 2011.

[22] B.-R. Lin and T.-L. Hung, "High-power-factor single-phase switch clamped rectifier," IEE Proceedings-Electric Power Applications, vol. 149 , no. 3, pp. 208-216, 2002.

[23] N. B. H. Youssef, K. Al-Haddad, and H. Y. Kanaan, "Real-time implementation of a discrete nonlinearity compensating multiloops control technique for a $1.5-\mathrm{kW}$ three-phase/switch/level Vienna converter," IEEE Trans. Ind. Electron., vol. 55, no. 3, pp. 1225-1234, 2008.
[24] N. B. H. Youssef, K. Al-Haddad, and H. Y. Kanaan, "Large-signal modeling and steady-state analysis of a $1.5-\mathrm{kW}$ threephase/switch/level (Vienna) rectifier with experimental validation," IEEE Trans. Ind. Electron., vol. 55, no. 3, pp. 1213-1224, 2008.

[25] N. Rahim and J. Jalil, "Single-phase five-level PWM rectifier," in Technical Postgraduates (TECHPOS), 2009 International Conference for, 2009, pp. 1-4.

[26] C. A. Teixeira, D. G. Holmes, and B. P. McGrath, "Single-phase semi-bridge five-level flying-capacitor rectifier," IEEE Trans. Ind. Applications, vol. 49, no. 5, pp. 2158-2166, 2013.

[27] T. Soeiro, M. Ortmann, and M. Heldwein, "Three-phase five-level bidirectional buck-+ boosttype PFC converter for DC distribution systems," in IEEE International Conference on Industrial Technology (ICIT), 2013, pp. 928-933.

[28] H. Vahedi, P.-A. Labbe, H. Y. Kanaan, H. F. Blanchette, and K. AlHaddad, "A New Five-Level Buck-Boost Active Rectifier," in IEEE International Conference on Industrial Technology (ICIT), Spain, 2015, pp. 2559-2564.

[29] H. Vahedi and K. Al-Haddad, "A Novel Multilevel Multi-Output Bidirectional Active Buck PFC Rectifier," IEEE Trans. Ind. Electron., vol. PP, no. 99, pp. 1-1, 2016.

[30] V. Monteiro, J. C. Ferreira, A. A. N. Melendez, and J. L. Afonso, "Model Predictive Control Applied to an Improved Five-Level Bidirectional Converter," IEEE Trans. Ind. Electron., vol. PP, no. 99, pp. 1-1, 2016.

[31] H. Vahedi, A. Chandra, and K. Al-Haddad, "Five-Level ReducedSwitch-Count Boost PFC Rectifier with Multicarrier PWM," in ECCE 2015-Energy Conversion Congress \& Exposition, Canada, 2015, pp. 2413-2420.

[32] B.-R. Lin and T.-L. Hung, "High-power-factor single-phase switch clamped rectifier," IEE Proc. Electric Power Applications, vol. 149, no. 3, pp. 208-216, 2002.

[33] H. Vahedi, E. Pashajavid, and K. Al-Haddad, "Fixed-band fixedfrequency hysteresis current control used In APFs," in IECON 2012-38th Annual Conference on IEEE Industrial Electronics Society, 2012, pp. 5944-5948.

[34] H. Vahedi and K. Al-Haddad, "Real-Time Implementation of a Packed U-Cell Seven-Level Inverter with Low Switching Frequency Voltage Regulator," IEEE Trans. Power Electron., vol. 31, no. 8, pp. 5967-5973, 2016.

[35] H. Hafezi, E. Akpinar, and A. Balikci, "Cascade PI controller for single-phase STATCOM," in 16th International Power Electronics and Motion Control Conference and Exposition (PEMC), 2014, pp. 88-93.

[36] R. Teodorescu, F. Blaabjerg, M. Liserre, and P. C. Loh, "Proportional-resonant controllers and filters for grid-connected voltage-source converters," IEE Proc. Electric Power Applications, vol. 153 , no. 5 , pp. 750-762, 2006.

[37] H. Vahedi and K. Al-Haddad, "Single-Phase Single-Switch Vienna Rectifier as Electric Vehicle PFC Battery Charger," in VPPC 2015Vehicular Power and Propulsion Conference, Canada, 2015, pp. 750-755.

[38] H. Vahedi, P.-A. Labbé, and K. Al-Haddad, "Balancing Three-Level NPC Inverter DC Bus Using Closed-Loop SVM: Real Time Implementation and Investigation," IET Power Electronics, vol. PP, no. 99 , pp. 1-1, 2016.

[39] IEEE, "IEEE Recommended Practice and Requirements for Harmonic Control in Electric Power Systems," in IEEE Std 519-2014 (Revision of IEEE Std 519-1992), ed, 2014, pp. 1-29. 


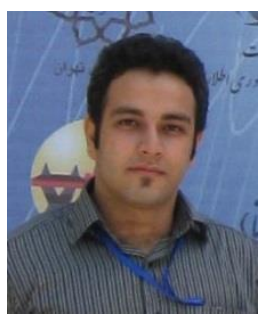

Hani Vahedi (S'10) was born in Sari, IRAN, in 1986. He received his B.Sc. and M.Sc. degrees both in electrical engineering from $\mathrm{K}$. N. Toosi University of Technology (KNTU), Tehran, IRAN in 2008 and Babol University of Technology, Babol, IRAN in 2011, respectively.

$\mathrm{He}$ is currently pursuing his $\mathrm{PhD}$ at the École de Technologie Superieure (ÉTS), University of Quebec, in Montreal, Canada, as a member of Groupe de Recherche en Électronique de Puissance et Commande Industrielle (GRÉPCI). His research interests include power electronics multilevel converters topology, control and modulation techniques, power quality, active power filter, and their applications into smart grid, renewable energy conversion, UPS, battery chargers and electric vehicles.

$\mathrm{He}$ is an active member of IEEE Industrial Electronics Society and its Student \& Young Professionals committee.

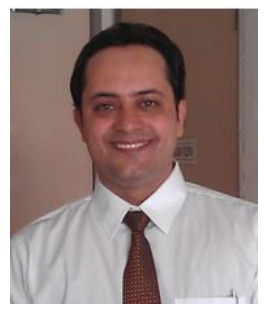

Ali Asghar Shojaei received the B.Sc degree from Islamic Azad University of Bojnourd, Bojnourd, Iran, in 2007. Then he pursued and received the M. Eng and $\mathrm{PhD}$ degrees in electrical engineering both from Universiti Teknologi Malaysia in 2009 and 2014, respectively.

Since 2010, he has been a Researcher in the Centre for Artificial Intelligence and Robotics, University Technology of Malaysia. Currently he is an assistant professor at Islamic Azad University, Neyshabur branch. His research areas include artificial intelligence applications on power system Stability and power electronics converters as well as designing neural network for power converter control in islanded and grid-connected modes.

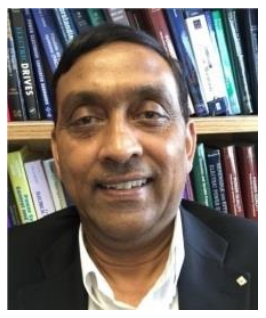

Ambrish Chandra (SM'99-F'14) received the Electrical engineering degree from the University of Roorkee [now Indian Institute of Technology (IIT)], Roorkee, India, in 1977, the M.Tech. degree in power apparatus and systems from the IIT, New Delhi, India, in 1980, and the Ph.D. degree from the University of Calgary, Calgary, $\mathrm{AB}$, Canada, in 1987. From 2012 to 2015, he was the Director of the graduate program on "renewable energy and energy efficiency" at the École de technologie supérieure (ETS), Université du Québec,, Montréal, QC, Canada, where since 1994, he has been a Professor with the Department of Electrical Engineering. His research interests include power quality, active filters, static reactive power compensation, flexible ac transmission systems (FACTS), and control and integration of renewable energy resources. He has coauthored the book Power Quality-Problems and Mitigation Techniques (Wiley, 2015). He is a Distinguished Lecturer of IEEE Power and Energy Society and also of IEEE Industry Application Society. Dr. Chandra is an Associate Editor of the IEEE Transactions on Industrial Electronics. He is a Professional Engineer in the Province of Quebec, Canada.

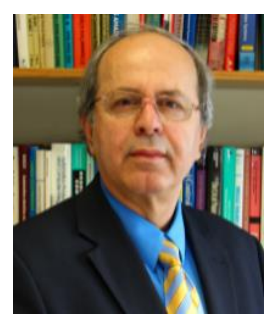

Kamal Al-Haddad (S'82-M'88-SM'92-F'07) received the B.Sc.A. and M.Sc.A. degrees from the University of Québec à Trois-Rivières, Canada, in 1982 and 1984, respectively, and the Ph.D. degree from the Institute National Polythechnique, Toulouse, France, in 1988. Since June 1990, he has been a Professor with the Electrical Engineering Department, École de Technologie Supérieure (ETS), Montreal, QC, where he has been the holder of the Canada Research Chair in Electric Energy Conversion and Power Electronics since 2002. He has supervised more than $100 \mathrm{Ph} . \mathrm{D}$. and M.Sc.A. students working in the field of power electronics. He is a Consultant and has established very solid link with many Canadian industries working in the field of power electronics, electric transportation, aeronautics, and telecommunications. He has coauthored more than 500 transactions and conference papers. His fields of interest are in high efficient static power converters, harmonics and reactive power control using hybrid filters, switch mode and resonant converters including the modeling, control, and development of prototypes for various industrial applications in electric traction, renewable energy, power supplies for drives, telecommunication, etc. Prof. Al-Haddad is a fellow member of the Canadian Academy of Engineering. He is IEEE IES President 2016-2017, Associate editor of the Transactions on Industrial Informatics, IES Distinguished Lecturer and recipient of the Dr.-Ing. Eugene Mittelmann Achievement Award. 